\title{
Model Dasar Pengembangan Business Model Canvas ke Balanced Scorecard (Studi Kasus: PT. Boma Bisma Indra)
}

\author{
Dewi LK., Nasution AH., dan Noer BA. \\ Departemen Manajemen Bisnis, Fakultas Bisnis dan Manajenen Teknologi, ITS \\ Jl. Arief Rahman Hakim, Surabaya 60111 Indonesia \\ e-mail: armanhakim.nasution@gmail.com
}

\begin{abstract}
Abstrak-Suatu perusahaan perlu memiliki pengukuran kinerja, hal tersebut dilakukan untuk mengetahui seberapa besar usaha yang telah dilakukan oleh perusahaan dalam mencapai tujuannya. Adapun Business Model Canvas (BMC) dapat digunakan sebagai alat untuk mengetahui arsitektur bisnis pada suatu perusahaan. Penelitian ini bertujuan untuk menganalisis (BMC) eksisiting yang kemudian dikembangkan menjadi Balanced Scorecard (BSC) sebagai model pengukuran kinerjanya sehingga dapat dijadikan sebagai arahan strategi perusahaan. Penelitian ini menggunakan data dari PT. BBI dengan pendekatan eksploratif melalui metode interview kepada para manajer dan Board of Director PT. BBI. Hasil yang diperoleh berupa 13 strategi obyektif (SO) yaitu menurunkan beban usaha, meningkatkan kepuasan pelanggan, meningkatkan loyalitas pelanggan, meningkatkan produksi untuk setiap sektor produk, meningkatkan efektifitas pemasaran, memperluas pangsa pasar, meningkatkan jumlah partner strategis, meningkatkan on time delivery produk, melaksanakan reward dan punishment, meningkatkan produktifitas SDM, dan meningkatkan investasi untuk sistem kelola perusahaan.
\end{abstract}

Kata Kunci-Balanced Scorecard, Bisnis Model Kanvas, Pengukuran Kinerja

\section{PENDAHULUAN}

$\mathrm{I}_{\mathrm{b}}^{\mathrm{N}}$ NDUSTRI manufaktur merupakan penyumbang tertinggi bagi PDB Indonesia yakni sebesar 18,1\% pada tahun 2016 dan untuk tahun selanjutnya Kementrian Perindustrian menargetkan industri manufaktur dapat menyumbang sebanyak $19 \%$ terhadap pertumbuhan PDB[1]. Dengan demikian industri manufaktur perlu meningkatkan kinerja yang dimilikinya. Adanya pengukuran kinerja diperlukan untuk mengetahui ukuran usaha yang telah dilakukan perusahaan. Seluruh sektor baik negeri maupun swasta perlu mengadakan pengukuran kinerja untuk mengembangkan, menumbuhkan dan mempertahankan eksistensinya pada industri yang kompetitif [2].

Salah satu perusahaan manufaktur di Indonesia yang saat ini memerlukan pengukuran kinerja untuk mengevaluasi usahanya adalah PT. Boma Bisma Indra (PT. BBI). PT. BBI merupakan salah satu perusahaan manufaktur BUMN yang memiliki kapasitas EPC (Engineering, Procurement, Construction) pada pembangkit listrik, kilang minyak, dan proses petro kimia. PT. BBI mengalami beberapa masalah dalam pengelolaan perusahaan diantaranya: keuangan dan sumber daya manusia yang berdampak ke berbagai aspek operasional perusahaan. Masalah keuangan yang dialami oleh PT. BBI yakni terjadinya kenaikan dan penurunan laba selama tahun 2011-2015, pada tahun 2010-2015 terjadi kenaikan jumlah hutang., serta target perusahaan yang tidak tercapai. Oleh karenanya PT. BBI perlu melakukan pengukuran kinerja guna mengetahui efektifitas dan efisiensi perusahaan dari segi program, proses bisnis serta sumber daya yang dimiliki.

Salah satu metode yang dapat digunakan dalam pengukuran kinerja ialah balanced scorecard (BSC). BSC merupakan alat manajemen yang mampu membantu perusahaan dalam mengidentifikasi visi dan strateginya dan menjadikannya suatu aksi[3]. Penelitian ini bermaksud membuat konsep pengukuran kinerja untuk PT. BBI melalui integrasi Business Model Canvas (BMC) pada BSC sebab bisnis model merupakan gambaran isi, struktur, dan aturan transaksi yang dirancang guna menciptakan nilai melalui pengembangan peluang bisnis[4].

\section{TINJAUAN PUSTAKA}

\section{A. Strategi Perusahaan}

Strategi telah dilakukan sebagai keterampilan manajemen (administrasi, kepemimpinan, berbicara di depan umum, dan kekuatan)[5]. Secara umum dapat disimpulkan bahwa strategi merupakan kemampuan dan keterampilan perusahaan dalam berbagai aspek untuk mencapai dan mewujudkan tujuannya.

\section{B. Business Model Canvas (BMC)}

Bisnis model merupakan metode rasional bagi perusahaan dalam menciptakan, menyampaikan nilai tambah serta menangkap peluang[6]. BMC memiliki sembilan blok yang terdiri dari value propositions, customer segments, customer relationships, channels, revenue stream, key activities, key resources, key partners, cost structure.

\section{Manajemen Kinerja}

Manajemen kinerja ialah peningkatan sinkronisasi untuk menciptakan nilai untuk dan dari customer dengan hasil penciptaan nilai ekonomi untuk pemilik dan juga stockholders[7]. Sedangkan untuk mengukur efisiensi dan efektifitas suatu tindakan atau kegiatan dalam implementasi strategi dilakukan pengukuran kinerja.

\section{Balanced Scorecard (BSC)}

BSC ialah alat yang digunakan untuk mengukur kinerja 
perusahaan dari hasil implementasi strategis yang dimiliki oleh perusahaan dan bertujuan untuk membuat strategi bisnis lebih terukur dan konkrit[8]. BSC terdiri dari empat perspektif yaitu perspektif keuangan (financial) yang menjelaskan cara untuk memuaskan shareholders, perspektif pelanggan (customer perspective) tentang cara menjaga hubungan dengan pelanggan, proses internal (internal process) menjelaskan tentang proses yang dapat dinilai sebagai added value perusahaan, dan juga pembelajaran dan pertumbuhan (learning and growth) tentang cara agar perusahaan dapat terus belajar dan tumbuh (improvisasi kinerjanya).

\section{E. Translate BMC to BSC}

Untuk mengintegrasi BMC pada BSC penelitian ini mengembangkan konsep yang dikemukakan oleh Richardson (2014)[9] yang memberikan gambaran serta arahan dalam menerjemahkan model bisnis BMC menjadi konsep pengukuran kinerja BSC seperti yang ada pada gambar 1 .
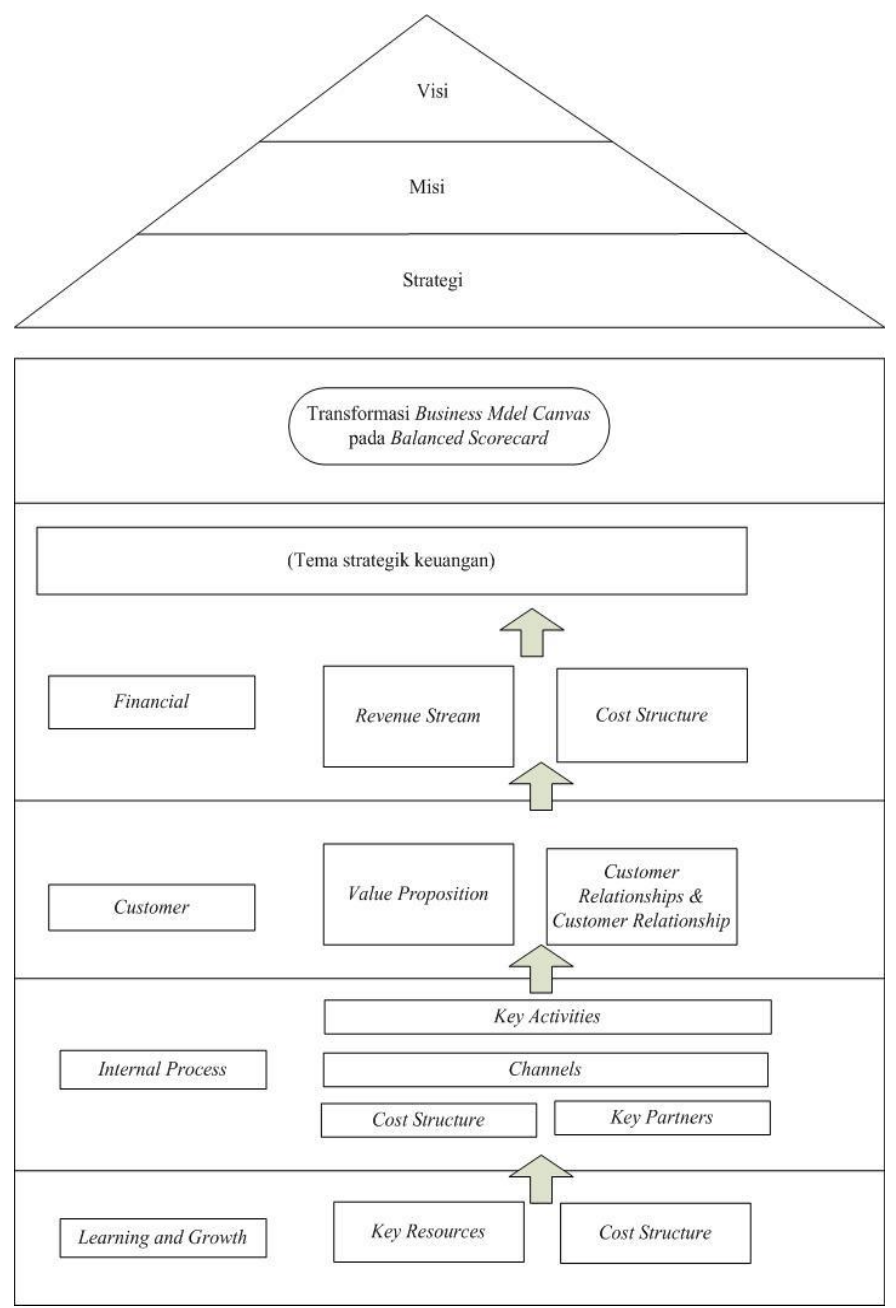

Gambar 1. Konsep terjememahan BMC ke BSC

\section{METODE PENELITIAN}

\section{A. Jenis Data}

Data yang digunakan pada penelitian ini ialah data primer dan data sekunder. Data primer didapatkan dari hasil wawancara semi-terstruktur dengan perwakilan dari PT. BBI.
Data sekunder didapatkan dari dokumen perusahaan diantaranya laporan keuangan, blue print rencana jangka panjang.

\section{B. Pengumpulan Data}

Pengumpulan data dilakukan dengan observasi langsung dan wawancara secara semi-tertruktur dengan pihak perusahaan yaitu middle management dan top management perusahaan. Selain menanyakan perihal kondisi eksisting wawancara juga dilakukan untuk menentukan rancangan BSC dari PT. BBI.

\section{Analisis Data}

Setelah melakukan pengumpulan data dilakukan analisis data secara deskriptif. Hasil analisis data digunakan untuk menentukan perumusan BSC. Perumusan tersebut dilakukan melalui diskusi dengan pihak perusahaan dan disesuaikan dengan masalah yang dihadapi perusahaan.

\section{PENGUMPULAN DATA DAN ANALISIS HASIL}

\section{A. Kondisi Eksisting Perusahaan}

Pada aspek keuangan masalah yang dihadapi PT. BBI yakni kenaikan dan penurunan laba bersih dari tahun 2012 hingga 2015 hal tersebut mengakibatkan berkurangnya kepercayaan konsumen terhadap PT. BBI sebagai pelaksana proyek sehingga terjadi penurunan penjualan dan menurunnya reputasi perusahaan di mata konsumen. Pada aspek pelanggan PT. BBI memiliki pelanggan dari dalam dan luar negeri. Dalam mengerjakan produksi atau proyeknya PT. BBI dapat menjadi sub-con ataupun main-con tergantung pada proyek atau pesanan yang diperolehnya. Untuk segi produksi masalah yang dihadapi yakni perencanaan produksi yang tidak terlaksana dengan baik salah satu penyebabnya ialah ketersediaan modal yang diperlukan untuk aktivitas produksi dalam pembelian bahan baku. Karena hal tersebut pembelian bahan baku mengalami keterlambatan dan pelaksanaan produksi mengalami kemunduran waktu. Pada aspek SDM saat ini komposisi terbesar SDM PT. BBI memiliki usia $>49$ tahun dan belum dilakukan proses regenerasi secara masif.

\section{B. BMC Eksisting}

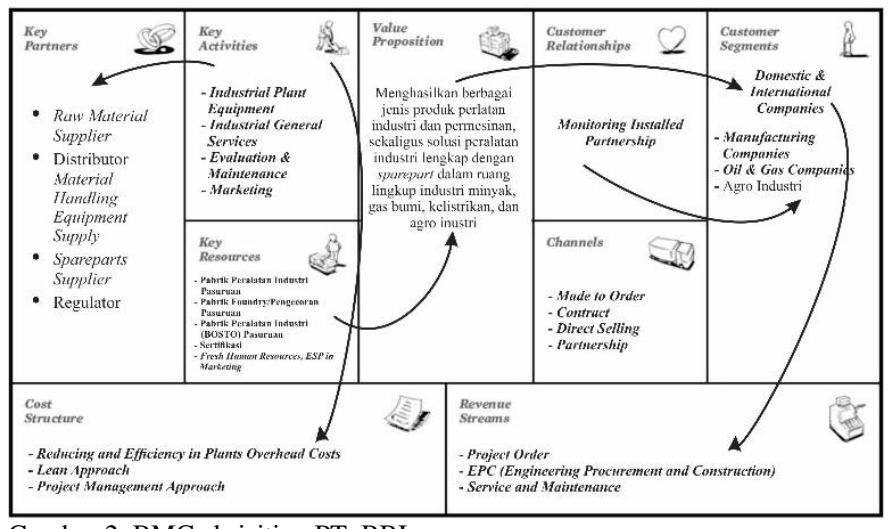

Gambar 2. BMC eksisiting PT. BBI

Gambar 2 merupakan gambaran BMC eksisting dari PT. BBI. Terdapat 9 blok yang saling terkait. 


\section{Value Propositions}

VP yang diberikan oleh PT. BBI pada konsumennya yakni penyediaan produk peralatan industri dan permesinan yang fokus pada industri konversi energi pada ruang lingkup industri minyak dan gas bumi, kelistrikan, dan agro industri serta sparepart nya dengan kualitas yang sesuai standar internasional. Produk-produk tersebut tidak diproduksi secara masal karena kapasitas atau ukurannya disesuaikan dengan permintaan pelanggan. Beragamnya keinginan pelanggan membuat PT. BBI memiliki kemampuan dalam memenuhi berbagai spesifikasi produk, hal tersebut dapat dimanfaatkan PT. BBI sebagai added value untuk memperluas pangsa pasarnya.

\section{Customer Segments}

Pelanggan dari PT. BBI yakni perusahaan baik dari dalam maupun luar negeri yang bergerak pada industri manufaktur, minyak dan gas, agro industri, dan kelistrikan. memiliki kemampuan dalam memenuhi berbagai spesifikasi produk, hal tersebut dapat dimanfaatkan PT. BBI sebagai added value untuk memperluas pangsa pasarnya.

\section{E. Customer Relationship}

Dalam menjalin hubungan baik dengan customer dilakukan dengan memonitor partner yang telah bekerja sama dengan PT. BBI melalui kunjungan perusahaan, menerima kritik dan saran konsumen dalam bentuk kuesioner feedback customer yang diberikan setelah menyelesaikan proyek, selain itu adanya jaminan atau after sales service juga diberikan bagi pelanggan yang memesan produk kepada PT. BBI. Namun adanya feedback melalui kuesioner yang bersifat kuantitatif dalam mengukur kepuasan pelanggan belum diterapkan pada setiap lini usaha PT. BBI sehingga PT. BBI belum mampu mengevaluasi diri secara maksimal dalam memenuhi kebutuuhan pelanggan untuk itu dapat dikatakan bahwa treatment bagi pelanggan belum dilakukan secara merata pada setiap divisi PT. BBI.

\section{F. Channels}

Penyampaian VP pada customer melalui pemesanan yang dilakukan oleh customer, kerjasama, penjualan atau penawaran secara langsung pada perusahaan yang diprospek, serta melalui partnership dengan perusahaan sejenis untuk mengerjakan suatu proyek bersama. PT. BBI kerap menjadi sub-con bagi perusahaan lain. Adapun peran sebagai main-con dapat dicapai lebih banyak pada agro industri yakni pembangunan pabrik kelapa sawit. Dengan demikian PT. BBI sebaiknya memperbanyak melakukan kerjasama dengan pihak-pihak pada agro industri agar peran sebagai main-con dapat dilaksanakan dan menjadi sumber pemasukan yang baik bagi perusahaan.

\section{G. Revenue Streams}

Pendapatan yang diperoleh PT. Boma Bisma Indra berasal dari proyek, EPC, dan service and maintenance yang dipesan oleh konsumen luar negeri maupun dalam negeri. Pendapatan sebagai main-con didapat lebih banyak saat menangani agro industri yakni pabrik kelapa sawit. Pendapatan terbanyak saat ini diperoleh perusahaan dari agro industri tersebut sehingga sebaiknya PT. BBI melakukan pengembangan pada bidang tersebut seupaya menjadi keuntungan yang baik bagi perusahaan.

\section{H. Key Resources}

Key resources ialah modal utama PT. BBI dalam menciptakan value. Dalam hal SDM PT. BBI menghadapi beberapa permasalahan yakni usia SDM yang sudah tidak produktif dan menjelang pensiun serta motivasi bekerja yang rendah sehingga PT. BBI cukup sulit mengembangkan SDM nya. Karena hal tersebut PT. BBI perlu melakukan regenerasi SDM dengan semangat kerja yang baru.

\section{Key Partners}

PT. BBI memiliki jaringan kerjasama untuk melancarkan proses bisnisnya dengan para distributor dan suppliers bahan baku dan material, pihak distributor maupun suppliers merupakan pihak yang telah diuji terlebih dahulu sehingga dipercaya untuk memenuhi bahan baku yang diperlukan. Adanya jaringan kerjasama selain membantu operasional juga secara langsung maupun tidak langsung membantu PT. BBI dalam hal pemasaran yang bermanfaat bagi produktifitas perusahaan.

\section{J. Key Activities}

Beberapa aktivitas yang ada pada PT. BBI diantaranya produksi peralatan industri, jasa perbaikan alat-alat industri, EPC, evaluasi dan pemeliharaan sumber daya baik fisik maupun manusia untuk dapat menciptakan value propositions seperti yang dibutuhkan pelanggan, serta aktivitas pemasaran untuk dapat meningkatkan penjualan produk dan menciptakan citra yang baik bagi perusahaan. Kegiatan pemasaran merupakan aktifitas yang sangat mendukung perolehan customer segments bagi PT. BBI sehingga memberikan pemasukan namun aktifitas tersebut terutama yang berkaitan dengan penciptaan citra yang baik belum sepenuhya dilakukan dengan baik oleh PT. BBI sehingga perlu upaya pembenahan aktifitas pemasaran terutama dalam hal branding.

\section{K. Cost Structure}

Biaya yang dikeluarkan oleh PT. BBI untuk melaksanakan proses bisnisnya diantaranya biaya produksi (overhead), penggajian karyawan yang dicanangkan melaui production planning, untuk dapat melaksanakan efiensi pengeluaran tersebut dilakukan manajemen proyek serta lean approach pada perusahaan namun nyatanya perusahaan belum mampu mengelola pengeluaran secara baik terutama dalam hal operasional perusahaan. Hal tersebut dikarenakan kegiatan yang dilakukan tidak sesuai dengan rencana sehingga menyebabkan kerugian bagi perusahaan. Dengan demikian perusahaan perlu mengkaji sistem manajemen proyek yang dimilikinya.

\section{Rancangan BSC}

Rancangan SO BSC didapatkan melalui hasil analisis kondisi eksisting dan telah disetujui oleh Board of Director PT. BBI. SO yang dihasilkan sebanyak 13 butir dengan rincian pada tabel 1 .

Selanjutnya dilakukan pembobotan terhadap masingmasing perpektif BSC. Pembobotan tersebut berfungsi sebagai acuan perusahaan guna membagi biaya operasional perusahaan untuk masing-masing perspektif bila terdapat 
suatu program yang ingin dijalankan pada perspektif tersebut. Adapun pembobotan tersebut dilakukan dengan cara[10]:

Bobot perspektif $=\frac{\text { Jumlah strategi obyektif perspektif }}{\text { Jumlah strategi obyektif seluruhnya }}$

Sehingga hasil pembobotan masing-masing perspektif yakni pada tabel 2. Bobot tertinggi yakni perspektif Internal Business Process sebesar $38 \%$ hal tersebut dikarenakan PT. BBI perlu melakukan banyak perbaikan pada kegiatan operasionalnya, selanjutnya adalah financial dan learning and growth masing-masing sebesar $23 \%$, dan terakhir perspektif customer sebesar $15 \%$.

Tabel 1.

Rancangan SO PT. BBI

\begin{tabular}{|c|c|c|c|}
\hline Perspektif & Tematik & $\begin{array}{l}\text { Building } \\
\text { Blocks BMC }\end{array}$ & Strategi Obyektif \\
\hline \multirow[t]{3}{*}{ Financial } & \multirow[t]{3}{*}{$\begin{array}{l}\text { Financial } \\
\text { Healthier }\end{array}$} & $\begin{array}{l}\text { Revenue } \\
\text { Stream }\end{array}$ & Meningkatkan pendapatan \\
\hline & & Cost structure & Menurunkan beban hutang \\
\hline & & & Menurunkan beban usaha \\
\hline \multirow[t]{2}{*}{ Customer } & $\begin{array}{l}\text { Customer } \\
\text { Satisfaction }\end{array}$ & $\begin{array}{c}\text { Value } \\
\text { Proposition }\end{array}$ & $\begin{array}{l}\text { Meningkatkan kepuasan } \\
\text { pelanggan }\end{array}$ \\
\hline & $\begin{array}{l}\text { Customer } \\
\text { Loyalty }\end{array}$ & $\begin{array}{l}\text { Customer } \\
\text { Relationship } \\
\text { \& Customer } \\
\text { Segments }\end{array}$ & $\begin{array}{l}\text { Meningkatkan loyalitas } \\
\text { pelanggan }\end{array}$ \\
\hline \multirow[t]{5}{*}{$\begin{array}{c}\text { Internal Business } \\
\text { Process }\end{array}$} & \multirow[t]{2}{*}{$\begin{array}{l}\text { Increase } \\
\text { Productivity }\end{array}$} & Key activities & $\begin{array}{l}\text { Meningkatan produksi untuk } \\
\text { setiap produk divisi }\end{array}$ \\
\hline & & & $\begin{array}{l}\text { Meningkatkan efektivitas } \\
\text { pemasaran }\end{array}$ \\
\hline & \multirow{2}{*}{$\begin{array}{c}\text { Quantity } \\
\text { Partnership }\end{array}$} & Channels & Memperluas pangsa pasar \\
\hline & & Key Partners & $\begin{array}{l}\text { Meningkatkan jumlah partner } \\
\text { strategis }\end{array}$ \\
\hline & $\begin{array}{l}\text { Operational } \\
\text { Excellence }\end{array}$ & $\begin{array}{c}\text { Cost } \\
\text { Structure }\end{array}$ & $\begin{array}{l}\text { Meningkatkan on time delivery } \\
\text { produk }\end{array}$ \\
\hline \multirow[t]{3}{*}{ Learning \& Growth } & $\begin{array}{l}\text { Profesional } \\
\quad \text { and } \\
\text { Efectiveness } \\
\text { Organization }\end{array}$ & $\begin{array}{c}\text { Key } \\
\text { Resources }\end{array}$ & $\begin{array}{l}\text { Melaksanakan reward and } \\
\text { punishment }\end{array}$ \\
\hline & $\begin{array}{l}\text { Employee } \\
\text { productivity }\end{array}$ & & $\begin{array}{l}\text { Meningkatkan produktivitas } \\
\text { SDM }\end{array}$ \\
\hline & $\begin{array}{c}\text { Business and } \\
\text { Technology } \\
\text { Concept }\end{array}$ & Cost structure & $\begin{array}{l}\text { Meningkatkan investasi } \\
\text { teknologi untuk sistem kelola } \\
\text { perusahaan }\end{array}$ \\
\hline
\end{tabular}

Tabel 2.

Pembobotan BSC

\begin{tabular}{lcc}
\hline \multicolumn{1}{c}{ Perspektif } & Jumlah SO & Bobot \\
\hline Financial & 3 & $23 \%$ \\
Customer & 2 & $15 \%$ \\
Internal Business Process & 5 & $38 \%$ \\
Learning \& Growth & 3 & $23 \%$ \\
\hline & 13 & $100 \%$ \\
\hline
\end{tabular}

\section{KESIMPULAN}

PT. BBI merupakan perusahaan manufaktur yang memiliki value preposition menghasilkan berbagai jenis produk peralatan industri dan permesinan lengkap untuk industri minyak dan gas bumi, industri kelistrikan, dan industri agro industri. Dalam mengantarkan VP tersebut PT. BBI melakukan kerjasama dengan berbagai pihak diantaranya supplier, instansi Pemerintah maupun swasta hal tersebut dinilai baik sebab mampu menjadi media kerjasama untuk meningkatkan produktifitas. Cara PT. BBI memperoleh pelanggan dengan mengikuti tender, melakukan kerjasama dengan instansi lain baik Pemerintah maupun swasta serta di dalam maupun luar negeri. Beragamnya jenis pelanggan yang dilayani menjadikan PT. BBI memiliki kemampuan untuk memenuhi kebutuhan berbagai segmen pelanggan. Kegiatan produksinya terdiri dari produksi peralatan industri, jasa perbaikan alat-alat industri, EPC, evaluasi dan pemeliharaan sumber daya baik fisik maupun manusia, serta aktivitas pemasaran. Adapun sumber daya yang dimiliki perusahaan terdiri dari pabrik serta SDM dengan keterampilan yang telah terverifikasi. Dari gambaran tersebut PT. BBI memiliki kemampuan untuk terus mempertahankan dan mengembangkan bisnisnya secara berkelanjutan.

\section{DAFTAR PUSTAKA}

[1] S. P. Gareta, "Sella Panduarsa Gareta," 25 Mei 2016. [Online]. Available: http://www.antaranews.com/berita/563025/kemenperintargetkan-industri-manufaktur-sumbang-19-persen-pdb. [Diakses 30 September 2016].

[2] H. Goharrostami, M. M. Nejad, R. R. Nejad dan A. Abdollahi, "Structural equation modeling (SEM) of performance evaluation indices in General Directorate of youth and sport of Guilan Province with partial least squares (PLS)," Physical Education of Students, pp. 49-56, 2016.

[3] B. Morard, A. Stancu dan C. Jeannette, "THE RELATIONSHIP BETWEEN STRUCTURAL EQUATION MODELING AND BALANCED SCORECARD: EVIDENCE FROM A SWISS NON PROFIT ORGANIZATION," REVIEW OF BUSINESS \& FINANCE STUDIES, pp. 21-38, 2012.

[4] C. Z. a. R. Amit, "Business model design: An activity system perspective," Long Range Planning, pp. 216-226, 2010.

[5] E. W. Mainardes, J. J. Ferreira dan M. L. Raposo, "STRATEGY AND STRATEGIC MANAGEMENT CONCEPTS: ARE THEY RECOGNISED BY MANAGEMENT STUDENTS?," Business Administration and Management, pp. 43-61, 2014.

[6] A. Osterwalder dan Y. Pigneur, Business Model Generation, Amsterdam: Modderman Drukwerk, 2009.

[7] G. Cokins, Performance Management Integrating Strategy,Exseqution, Methodologies, Risk, and Analysis, United States of America: Wiley and SAS business series, 2009.

[8] R. S. Kaplan dan D. P. N. As, "Using the Balanced Scorecard as a Strategic Management System," Harvard Business Review, pp. 75-86, 1996.

[9] S. Richardson, "Business Model Canvas and Strategy Map Fusion - Your Best Approach for Business Success," 11 September 2014. [Online]. Available: https://www.linkedin.com/pulse/20140911153223-3251275business-model-canvas-and-strategy-map-fusion-your-best-approach-forbusiness-success.

[10] D. Norton, “The Unbalanced Scorecard,” 2000. 